\title{
The Elephant in the Room: Understanding Barriers to Students' Articulation of Diversity
}

\author{
Janice Gasker ${ }^{1}$, Heather A. Campbell LaBarre ${ }^{2}$ \\ ${ }^{1}$ Kutztown University of Pennsylvania, Kutztown, USA; ${ }^{2}$ Lehigh Valley Hospital, Allentown, USA \\ Email: gasker@kutztown.edu, heathercampbell@rcn.com
}

Received May $11^{\text {th }}, 2010$; revised July $13^{\text {th }}, 2010$; accepted July $20^{\text {th }}, 2010$.

\begin{abstract}
A scholarship competition designed to foster classroom discussion and introspection about diversity had few participants despite its cash prize. This paper explores undergraduates' view of the project via focus groups and reveals surprising depth in students' answers to the question of why students did not participate. Analysis uncovered emergent themes related to emotional discomfort with diversity in general and self reflection in particular. Implications include the conceptualization of "diversity," teaching methods, and instructors' professional development.
\end{abstract}

Keywords: Undergraduate, Diversity, Higher Education, Cultural Competency

\section{Introduction}

Vast differences in race, gender, ethnicity and many other variables increasingly characterize the face of the university; this diversity is generally seen as both necessary - due simply to demographics - and desirable - due to its potential for enhancing intellectual, social and personal development of students [1]. Unfortunately, neither the creation of a diverse student body nor education about diversity is simple. In response to the challenge, a social work program on a rapidly diversifying campus developed a scholarship program-The Social Work Prize: Celebrating Diversity to help undergraduates reinforce classroom learning and promote self reflection about diversity and cultural competence. The contest charged students to articulate some "celebration" of diversity in their own lives, and in return they could win a cash prize. Given the cash prize, organizers were astonished to find that few students applied for the prize. Students did not wish to participate, even when a classroom assignment corresponded exactly to the scholarship's specifications. Despite student input in tweaking the prize and refining its marketing to students over a five year period, each year fewer than ten of the 150-200 undergraduate students applied. Rate of participation began to be seen as a possible bellwether of students' comfort with the diversification of the campus and the curriculum. Consequently, it is the purpose of this paper to begin to identify the factors related to student partici- pation in the prize in the hopes of identifying some educational characteristics of successful discussion of diversity.

\section{Literature Review}

Issues in "diversity" in higher education curricula and programming were reviewed. During the project, the issue of students' anxiety surrounding diversity became a clear and significant theme. Consequently, anxiety and its subsequent resistance in the process of teaching and learning about diversity were examined as an iterative inquiry during the interview period. In addition, the effective pedagogy of diversity became a significant area of literature review, in part to avoid inadequate disconfirming evidence [2]. For the purposes of this paper, "diversity" is understood as it is presented in the primary textbook used by this group of students: "Diversity refers to the vast range of differences among people, including those related to race, ethnicity, cultural background, place of origin, age, physical and mental ability, spirituality, values, sexual orientation, and gender" [3].

\subsection{Benefits of Campus Diversity}

The educational benefits of a diversified campus are now under legal scrutiny, thus, researchers are beginning to fully explore the benefits of a diversified campus. Outcomes may be judged based on economics - graduation rates and graduates' income level [4], the analysis of faculty opinions [5], specific education outcomes [6], 
and student subjective assessments of interaction [7]. Methods for assessment of students' perceptions vary, including self reflection of personal beliefs and expectations upon entering college and in comparison to senior year experiences. A meta-analysis conducted by Gurin, et al. (2002) [7] concluded that whether the method was retrospective or longitudinal, using different samples and reporters, a wide variety of benefits to individuals and to campuses occurred as a result of campus diversification.

A self-report study focused on both interpersonal and skill-acquisition outcomes followed two cohorts totaling 1, 293 respondents of Asian-American, African-American, and Caucasian-Americans [8]. The first cohort graduated in 1989 with a diversity composition of 3\% Asian-American, 1\% Hispanic, 3\% African-American, and 94\% Caucasian-American. The second cohort graduated in 1994 with the minority population doubled [8]. The cohorts were questioned on interracial student interactions, and their alma mater's contribution to skill development.

Results suggested that all groups benefited from the increased diversity; however, Caucasians benefited most [8]. It is most important to note that the study found a diverse student body not only increased the likelihood of same race interactions but an overall development of skills and academic achievement for all groups [8]. This study and others [9] support the Gurin et al. (2002) [7] conclusion that the presence of diverse student combined with student-student interaction reaps skill and academic benefits.

\subsection{Pedagogy of Diversity}

Another facet of the diversification experience on campuses is education. While it seems self evident that education alone will not diversify a campus, diversification may also be necessary but insufficient. Resistance to education related to diversity has been manifested in both students and faculty, even in culturally sensitive social work programs [10]. Within programs, students may struggle with a firm definition of diversity, the importance of increased awareness, and knowledge of diverse populations while faculty members struggle with limited knowledge of diverse populations and unprepared class agendas focused on the work related to diverse populations [10].

Consequently, it is clear that both institutions and individual educators bear responsibility for achieving the benefits associated with the understanding of difference among people. While the university's task is diversification of the student body, the educator's challenge is to create an environment of cultural sensitivity and cultural competence to confront and overcome tension and resistance. Utilizing the concept of critical pedagogy, Red- mond (2010) [5] developed structured classroom discussions as 'safe space' for articulation of taboo or emotional topics. Modification of the classroom setting became necessary when the avoidance of perceived taboo topics resulted in tension within the classroom. The study identifies the instructor as a mediator to address issues in the classroom regardless of personal discomfort [5].

Instructor characteristics and those of the educational environment conducive to learning and skill building include diversified classrooms as the forum for developing sensitivity and skill building. Faculty members who are comfortable with addressing tension-filled student issues have been found to be instrumental to student development. On the other hand, faculty discomfort in addressing issues of diversity may strain the classroom setting by avoiding a teachable moment. Faculty must work introspectively to identify their own identity issues along with knowledge of the populations they serve in their classrooms to create a safe learning environment where it is possible to confront and discuss tensions. While faculty members may identify that practices of open discussion and forums for learning are present, underlying biases may discourage the faculty member from engaging in discussions focused on diversity. Garcia \& Van Soest (1997) [11] identified faculty members' awareness of personal comfort and recognition of their own diversity is important to avoid issues of counter-transference. Students may be influenced in a negative manner on the subject of diversity if a faculty member presents a strong point of view that is in contrast or attempting to correct student discussion [11]. Encouraging students to be open and verbalize both strengths and barriers is important to course planning. Allowing students to develop coursework may encourage independent learning and articulation of educational needs and barriers. Clear, strengths based objectives for class room structure in necessary along with grading focused on learning and quality of work, not political correctness [10]. Simply identifying tensions and resistance are typical when covering issues related to diversity and may inhibit questions by students. Open discussions regarding why diversity is important and student rationale for engaging in coursework may identify tensions that can be addressed and overcome. Creation of a supportive and proactive learning environment focused on recognition of student's efforts to engage in discussions is critical to developing self- recognition and normalization of the learning process [12-16].

In an attempt to create awareness to barriers surrounding the development of culturally competent skills, Messing (2004) [17] details specific tasks assigned to the classroom to identify bias and pejorative language. In a classroom structured activity, undergraduate students in a multicultural social work course were encouraged to de- 
velop an understanding of culturally competent practices through class discussion. Messing (2004) [17] developed a method to encourage peer feedback and discussion regarding the use of appropriate, disrespectful, or negative language. To develop culturally competent, nonbiased language, students were asked to "choose a characteristic or a population with more than one characteristic" and respond to several reflective questions. The questions elicited responses based on the student's beliefs, current knowledge, and issues or level of discomfort. The student submissions were integrated into a document of statements pulled from each paper with modifications made to each statement to protect the confidentially of each student as the statements are read aloud in class. The class is encouraged to rate each statement (as appropriate, disrespectful, or offensive) then process the statement. The peer discussion encourages students to be aware of biases and respond to pejorative statements in a safe environment. Messing's activity elicited positive responses from students, stating the activity encouraged awareness to personal biases and the importance of professional, culturally competent skill.

Awareness of personal bias is only the beginning of understanding diversity and developing cultural competence. Mills and Ballentyne (2010) [18] caution that expectations of change in student attitudes and functioning should not be too high: a single experience or even a short course is not likely to carry the students through a process of change. They suggest that the process moves from "self awareness / self-reflectiveness" to "openness" and finally to a "commitment to social justice". Likewise, in a study of 200 undergraduates, Gasker and Vafeas (2003) [19] found that a course on poverty which aimed to move students toward a structural explanation for poverty (i.e. away from blaming the victims of poverty) was valuable, but that "curriculum-wide effort to provide this material to students may be beneficial".

\subsection{Literature Review Summary}

It appears that the diversification of campuses is beneficial to all concerned, particularly Caucasian students. Simply increasing numbers of underrepresented groups does in fact appear to facilitate the understanding of difference and the development of skills necessary for improving interpersonal interaction. On the other hand, simply increasing numbers does not seem to be sufficient for developing the comfort level required by social work education to lay the ground-work for developing cultural competency. Effective teaching and learning seems to take place over time in situations where educators and students feel safe enough to risk vulnerability. Identifying the factors associated with creating this atmosphere of safety is a subject worthy of study.

\section{Methods}

Undergraduate students in three sections of a foundation level social work course and one section of a senior seminar course were offered the opportunity to participants in focus groups. Using a convenience sample, participants were chosen from "major only" courses that had a diversity assignment component. That is, all participants had been required to complete an assignment based on a diverse population. The assignment developed in relation to Council of Social Work Education standards, met submission criteria for The Social Work Prize: Celebrating Diversity.

One week prior to the focus groups, a graduate social work student (chosen as interviewer to reduce interview bias) engaged the classes with a brief discussion of the purpose of the groups. Confidentiality and informed consent were reviewed as necessary components of the focus groups. The focus groups, conducted during scheduled class time and time-limited to 30 minutes, would not impact the students' class participation grade.

During the initial classroom visit, potential participants were encouraged to ask questions or provide feedback to the interviewer regarding the purpose of the focus groups or the research project. On the day the focus groups were to be conducted, the interviewer re-entered all sections of undergraduate classes to restate the purpose and location of focus groups. Prior to the instructors' entrance, the interviewer disclosed the location of the focus group and exited the classroom. As the students entered the focus group room, the interviewer provided each participant with a brief, written description of the study. The interviewer encouraged any questions prior to the participants signing informed consent and completing the demographic questionnaire. The interviewer assured confidentiality and requested permission of all participants to audio record.

All data were recorded and transcribed prior to analysis. Atlas. ti provided a means for analysis, which was conducted through grounded theory's open coding methods [20]. Reliability was checked via independent coding and differences were resolved via discussion. Member checking was conducted with the focus groups in informal discussion following analysis.

\section{Findings}

Of the four focus groups, nineteen students (seventeen females) participated. Three females identified as racial minorities - one Black and two Hispanic - while one male independently identified himself as gay, which became an important part of that group's discussion.

Qualitative analysis of focus group feedback identified 
four possible barriers to participation in The Social Work Prize: Celebrating Diversity. Student emotional reaction to a perception of white privilege, and limited self reflection of personal areas of diversity were identified. Other identified barriers could be described as limited knowledge of diversity and a perceived or real inability to appropriately articulate issues related to diversity. Logistic issues of understanding of the submission, review, and awarding of the prize were also identified as potential barriers.

\subsection{Emotional Reactions to White Privilege}

"White privilege" is a category that was not named by students but emerged from the analysis of data. Primarily, the feeling was manifest in a pervasive discomfort related to various types of diversity, particularly those with which the students had no personal experience. Analysis revealed that students completed their class diversity assignments with a focus on populations familiar to the student. For unfamiliar areas of diversity, discomfort was expressed consistently in the focus groups. Participants seemed to feel that a barrier to submitting a diversity prize for public scrutiny was something like benefiting from the adversity of others. This seemed to be the case despite the scholarship's title "Celebrating Diversity" and its charge, to "explain some way you can celebrate diversity in your life." One student felt that asking a person of a different race or culture to discuss their experience would feel like "gawking" or staring at someone's "misfortune." Another student felt if there were an event to present submissions to the prize, people would look at her as if she "did not belong there" due to her (Caucasian) race.

\subsection{Self Reflection}

The ability to apply classroom knowledge related to diversity to their own situations emerged as the second potential barrier to participation in the prize. Students who did not apply for the prize in all groups stated that they felt they had "no diversity." Primarily, focus group participants discussed not feeling "diverse" based on racial identification. To them, Caucasian did not "count" as diverse. Students struggled to identify areas in personal diversity and stated initial ideas for submission to the prize would not be "diverse enough" for the prize. Somehow, although the prize instructions did not ask them to focus on their own aspects of diversity, they seemed to view "being diverse" as an entrance qualification. One student stated multiple times during the focus group that she did not feel "diverse" simply because she was Caucasian.

\subsection{Limited Knowledge of Diversity}

In addition to limited comfort or ability to self-identify as an individual with different characteristics, students also identified feeling uncomfortable with defining, identifying, or articulating diversity in a classroom or public setting. Students feared being regarded as ineffective or inappropriate is they could not identify their own diversity and avoided interaction with cultures dissimilar from their own. The focus group participants primarily viewed diversity as an emphasis on race, neither cultural or ethnic identification nor any other characteristic. One student articulated the understanding that diversity is not only associated with race, but her class project on diversity did not embrace the conceptualization.

One student related an experience in which she attempted to make an entry to the prize competition, but, per the student's report, her proposed diversity project was identified as "not diverse" by a faculty member. The student stated no other efforts were made to participate in the diversity prize after the interaction. The student verbalized feeling embarrassed and worried she might not belong in a helping profession if she could not identify diversity to faculty members.

\subsection{Logistic Knowledge of the Application Process}

When asked specifically to identify factors associated with participation or nonparticipation in the Prize, students identified communication of the availability of the prize as a possible barrier. While this may be a coping mechanism to avoid more serious issues, it was discussed fully in the groups and was assumed to be as valid as any other response in analysis. The focus group participants suggested that they were unaware that they could submit their class assignments as entries for the Prize. The focus groups discussed miscommunications regarding how projects were submitted, which faculty members were involved in judging the prize, and the benefits of participating.

All students inquired about the amount of money the prize generated for the student. The amount of money was a pivotal point for some students. Without knowing the dollar amount, the students reported that they were unsure if developing a submission would be worth their time and effort. Students were unaware of how the winner of the prize was honored. Discussions regarding fears of presenting the submissions in front of multiple faculty members or a large community of people were identified as barriers for students who struggled to feel comfortable in defining and articulating diversity.

\subsection{Student Suggestions}

Following the open-ended interview questions, students were asked specifically how the prize might be improved. Student suggestions to make the prize more accessible 
included creating a clearly designed brochure with attractive coloring. Students wanted to know the cash amount and which faculty members were involved in the project selection process. Clear articulation of what the entries were to include and clear definition of diversity provided with the application were identified as additional student suggestions. One focus group suggested a website with frequently asked questions regarding the competition. The group stated that limited understanding of the purpose of the prize may be a barrier to participation. Students felt the program should more clearly present purpose of the prize to encourage and motivate people to participate. Opening the prize to the entire university was identified as a method to generate more participation and engagement in the project.

\section{Limitations}

Limitations include the limited student participation in focus groups. More student feedback may have generated more diverse focus groups, more potential barriers and support for peer identified issues. The focus groups were conducted with a single researcher and audio recorded. After the focus groups were conducted, it was identified the tape or recorder had malfunctioned throughout the focus groups. Although extensive notes were taken, at times during the focus groups audio was lost.

Replication of the study would benefit from multiple focus groups with a larger amount of students matched to the institution's level of diversification. More than one group facilitator would benefit the project and provide additional observation in focus groups as well as notetaking support. Ensuring the adequacy of audio equipment will benefit the transcription of the data.

\section{Discussion}

Student voices clearly revealed a complex set of circumstances that come together to provide a barrier to their participation in this learning exercise. The diversification of college campuses has created a myriad of opportunities as well as emotional discomfort. For the focus group participants, these pressures ironically co-exist with uncomfortable feelings related to their own status as members of the majority "privileged" group. In addition, participants revealed a limited ability to self-reflect on their own elements of diversity and seemed to lack a cogent definition of the concept itself. These factors together contributed to the lack of participation in the project.

Other barriers were identified explicitly by the students themselves. These include a focus on the aesthetic value of the brochure advertising the prize along with the need for clear, directive language, submission expectations and disclosure of the cash prize amount as potential barriers to participation in the prize. Creating a brochure that demands the attention of a student and clearly states expectations of each submission as well as a clear definition of diversity was identified as a method to generate more participation. Students also expressed an interest in the level of cash prize as something that would dictate their participation. It is interesting to note, however, that this same cohort of students also produced a well-reasoned, well-attended protest of a campus event identified as "racist" (for no remuneration). It appears that emotional barriers are at least as powerful to students as logistic ones. Consequently, the development of a similar "diversity prize" may serve as an effective bellwether of student experiences with difference.

Perhaps most importantly, it appears from the literature and was suggested by at least one focus group that faculty need to recognize their own learning needs. Selfreflection around one's own diverse characteristics is necessary to develop the comfort level needed to seize teaching opportunities as they occur. Resistance in the classroom can be identified by feelings of guilt from perceived white privilege, limited self awareness, and competency issues of articulating diversity in a professional and unbiased manner. The literature indicates support for the focus group findings. A faculty effort to manage personal judgment of student responses encourages the engagement of students in the learning process [14].

Encouraging the learning process through class participation and activities across the curriculum can reduce anxiety regarding diversity and develop a forum of open discussion, but this requires faculty who are aware of personal and professional views. Through the utilization of critical theory and throughout the literature, faculty members are called on, then, encouraged to engage in introspective activities related to personal views and barriers regarding diversity. Finally, a program-wide, standardized definition of diversity may also be helpful to achieve uniformity and comfort with the concept. Indeed, the creation of a "program approved" definition may facilitate faculty professional growth. To achieve cultural competency, programs, faculty and students all need to be open to vulnerability and change.

\section{REFERENCES}

[1] D. W. Johnson and R. T. Johnson, "Multicultural Education and Human Relations: Valuing Diversity," Allyn and Bacon, Boston, 2002.

[2] R. L. Linn and F. Erikson, "Quantitative Methods," Macmillian, New York, 1990.

[3] K. K. K. Ashman and G. H. Hull, "Understanding," Gen- 
eralist Practice, Belmont, CA: Brooks/Cole, 2009.

[4] D. Bok and W. G. Bowen, "Access to Success," $A B A$ Journal, Vol. 85, No. 2, 1999, pp. 62-64.

[5] M. Redmond, "Safe Space Oddity: Revisiting Critical Pedagogy," Journal of Teaching in Social Work, Vol. 30, No. 1, 2010, pp. 1-14.

[6] E. C. Chang, "Cultural Differences in Optimism, Pessimism and Coping: Predictors of Subsequent Adjustment in Asian American and Caucasian American College Students," Journal of Counseling Psychology, Vol. 43, No. 1, 1996, pp. 113-123.

[7] P. Gurin, E. L. Dey, S. Hurtado and G. Gurin, "Diversity and Higher Education: Theory and Impact on Educational Outcomes," Harvard Educational Review, Vol. 72, No. 3, 2002, pp. 330-367.

[8] J. Luo and D. J. Drake, "Size Matters: Exploring the Education Value of Increasing Student Diversity," Presented at the Annual Forum of the Association for Institutional Research, 2002.

[9] A. W. Astin, "How Are Students Affected?" Change, Vol. 25, No. 2, 1993, pp. 44-50.

[10] K. Bashan and D. Miehls, "Introduction," Smith College Studies in Social Work, Vol. 74, No. 2, 2004, pp. 207-212.

[11] B. Garcia and S. D. V. Soest, "Teaching about Diversity and Oppression: Learning from the Analysis of Critical Classroom Events," Journal of Teaching in Social Work, Vol. 18, No. 1.2, 1999, pp. 149-167.

[12] C. Fields and S. D. O'Connor, "Affirmative Action," Change, Vol. 37, No. 5, 2005, p. 5.

[13] J. Torres and Jones, "You've Got to be Taught: MultiCultural Education for Social Workers," Journal of Teaching in Social Work, Vol. 15, No. 1/2, 1997, pp. 161-179.

[14] B. Garcia and S. D. V. Soest, "Changing Perceptions of Diversity and Oppression: MSW Students Discuss the Effects of a Required Course," Journal of Social Work Education, Vol. 33, No. 1, 1997, pp. 119-129.

[15] B. A. Nagda, "Intergroup Dialogues: An Innovative Approach to Teaching about Diversity and Justice in Social Work Programs," Journal of Social Work Education, Vol. 35, No. 5, 1999, pp. 433-449.

[16] S. C. Stakeman, "Educating Professionals for Proactive in a Multicultural Society: Understanding Oppression and Valuing Diversity," The Journal of Contemporary Human Services, Vol. 82, No. 6, 2001, pp. 612-622.

[17] L. Messing, "The Good, the Bad and the Ugly: A Teaching Innovation to Help Student Develop Cultural Com- petence," The Journal of Baccalaureate Social Work, Vol. 10, No. 1, 2004, pp. 61-74.

[18] J. Gasker and J. Vafeas, "Starting Where the Student is: Adapting Social Justice Curricula to Poverty Attitudes," The Journal of Baccalaureate Social Work, Vol. 9, No. 1, 2003, pp. 93-112.

[19] C. Mills and J. Ballentyne, "Pre-service Teachers' Dispositions towards Diversity: Arguing for a Developmental Hierarchy of Change," Teaching and Teacher Education: An International Journal of Research and Studies, Vol. 26, No. 3, 2010, pp. 447-454.

[20] A. Strauss and J. Corbin, "Basics of Qualitative Research: Grounded Theory Procedures and Techniques," Sage, Newbury Park, 1990.

[21] E. Lewis, "Continuing the Legacy: On the Importance of Praxis in the Education of Social Work Students and Teachers," In D. Schoem, L. Frenkel, X. Zungia and E. A. Lewis (Eds.), Multicultural Teaching in the University, 1993, pp. 26-36.

[22] J. H. Helms, L. T. M. Shakes, K. Henze, A. Saiani, J. Perry and A. Warren, "First Annual Diversity Challenge: 'How to Survive Teaching Courses on Race and Culture'," Journal of Multicultural Counseling and Development, Vol. 31, 2003, pp. 3-11.

[23] G. Janice, "The Social Work Prize: Celebrating Diversity," Pennsylvania, 2006.

[24] J. Mildred and X. Zuniga, "Working with Resistance to Diversity Issues in the Classroom: Lessons from Teacher Training and Multicultural Education," Smith College Studies in Social Work, Vol. 74, No. 2, 2004, pp. 359-375.

[25] G. W. Sazama, "Has Federal Student Aid Contributed to Equality in Higher Education?" American Journal of Economics \& Sociology, Vol. 51, No. 2, 1992, pp. 129147.

[26] A. Springer, "Update on Affirmative Action in Higher Education: A Current Legal Overview," American Association University Professors, Washington, DC, 2003.

[27] K. Syverud, "Expert Report of Kent D. Syverud in Grutter V. Bollinger," Peabody Journal of Education, Vol. 79, No. 2, pp. 136- 140.

[28] “US Department of Education," Legislation Regulations and Guidance," November, 2006. http://www.ed.gove/programs/ac/legislation.html

[29] "Facts on Affirmative Action and Higher Education," January, 2004. http://www.civilrights.org 